\title{
Text and Image Studies: Theory of East Asian Cultural Diffusion
}

\author{
I Lo-fen*
}

\begin{abstract}
The word 'Text' in Text and Image Studies encompasses sound/ language text, textual body, word/ literary text and image text. 'Image' represents not only pictorial illustrations, but also symbols, icons, logos/ trademarks and other forms of visual rhetoric, as well as videos, lines and printed material. Text and Image Studies offers valuable approaches in the investigation and analysis of the complexity of the interplay, interrelations and disjunctions between text and image in various forms of visual media. Chief subjects of interest include creativity and innovation, distribution and dissemination, sociopolitical implications, impact on consumerism, psychological effects on human cognition, etc.

The theoretical application of Text and Image Studies in the East Asian cultural exchange discussed in this article is the fruit of almost two decades of research. The article uses a seven-pronged approach - canonization, politicization, conceptualization, abstraction, localization, standardization, modularization- in the study of East Asian cultural exchange in variety of regions, time periods, and genre in an attempt to explore new research ideologies and theories.
\end{abstract}

\section{Prologue}

The word 'Text' in Text and Image Studies encompasses sound/ language text, textual body, word/ literary text and image text. 'Text' is presented in limitless forms and pique interpretive questions from readers and observers. Text references could be words, images, or audio and videos, as well as other media of communication.

'Image' represents not only pictorial illustrations, but also symbols, icons,

* I Lo fen 衣若芬 is an Associate Professor in the School of Humanities at Nanyang Technological University in Singapore 
logos/ trademarks and other forms of visual rhetoric, as well as videos, lines and printed material. The pictorial elements and visual impact of Chinese characters are also considered as images, albeit in the intangible form. As a corollary, the 'Text' and 'Image' in Text and Image Studies are not always mutually exclusive; at times, they could also influence and reflect each other. Text and Image Studies is concerned with the interrelationship between text and image, disjunctions between the two, and reflections of each other. Subjects of interest include creativity and innovation, social media, sociopolitical implications, consumerism, aesthetic consciousness etc. ${ }^{1}$

This article draws inferences from analysis of various case studies using a seven-pronged approach - canonization, politicization, conceptualization, abstraction, localization, standardization and modularization. These seven approaches influenced the processes of cultural diffusion, interaction, acceptance, derivation and formulation.

\section{Canonization}

Italian journalist and writer, Italo Calvino (1923-1985) in his book, Why Read the Classics? provided a definition for classics: "The classics are books that exert a peculiar influence, both when they refuse to be eradicated from the mind and when they conceal themselves in the folds of memory, camouflaging themselves as the collective or individual unconscious.".

Classics speak readers at a deep emotional level, evoking feelings that resonate with readers throughout generations and are an important part of the repertoire for readers to read over and over again. Exemplary works of art that have been accepted as classics are critiqued, evaluated and interpreted. Over time, the classics influence and add value to the cultures they pass through, thereby further strengthening their position as classics.

The process of a work of art in becoming a classic is known as 'canonization' and the steps are described by:

(i) Selection: The classic resonates with the readers, inspiring emotional responses, and becoming a part of their consciousness and life. Cognitive associations between memories from their readings and imagination lead readers to continue on their own cognitive pathways, thereby enriching their lives.

(ii) Evaluation: The positive or negative reviews by the writer's critics in contemporary and later eras affect the status of the classic in art

1 I Lo-fen, "The inscription on the portrait of Bai Juyi by Wuxue Zhuyuan (Mugaku Sogen): A Case Study of Text and Image Studies”(無學祖元贊《白樂天像》の文圖學的 研究). Studies of Bai Juyi(Tokyo)(白居易研究年報),17, pp. 96-124, Dec., 2016. (Translated by Morioka Yukari) 
history. The reviews are greatly influenced by aesthetic views held by the readers of that time, their personal outlooks on life as well as the world's outlook. The position of the work of art as a classic may be strengthened or weakened or it may even be completely dropped out in the list of classics.

(iii) Transmission: A classic piece of art has timeless quality and universal appeal. The more the channels of transmission for the classic, the broader the reach and scope, especially if it has been translated to other languages and/ or reproduced through other artistic media. The expression of a literary work using an illustration is one of the ways of dissemination by means of visual sensory. At times, it is not even necessary to use any text to establish rapport with the public.

Selection, evaluation and transmission drive the process of canonization of an art in the country and even transcends national boundaries. For example, the popularity of Bai Juyi's (772-846) Song of Everlasting Sorrow spread to Japan, Goryeo (present-day Korea), and Vietnam where it was held in high regard in the compilation of well-known poems. During the exploratory study of canonization of Song of Everlasting Sorrow in East Asia, it was discovered that folding screens and painting scrolls with this theme appeared in Japan from as early as the Heian era $(794-1185)$. Pictorials depicting Song of Everlasting Sorrow deepened its influence in Japan. In contrast, this theme was hardly depicted in China and Korea. Upon further investigation, the reason for the lack of interest was determined- Song dynasty scholars have a negative review of the poem, criticizing it for its deviation from the truth, sexual references and unacceptable standards of morality. This criticism is accepted and perpetuated in Korea. ${ }^{2}$

Despite the theme of Song of Everlasting Sorrow being uncommon in paintings in China and Korea during the ancient times and negative criticisms by contemporaries, the process of canonization of the poem was in no way impeded.

2 I Lo-fen, "The Canonization of Bai Juyi’s 'Song of Everlasting Sorrow' and Related Illustrations of the Poem in East Asia”(白居易〈長恨歌〉之經典化及其東亞相關圖繪簡 論). In Xin Ning, Dietrich Tschanz, Ching-I Tu eds., "Chinese Classics and Traditional Thought: Origin, Development, and Dialogue”(中國古代經典與傳統思想: 起源、流變與對話) . Confucius Institute at Rutgers University, U.S.A. pp. 225-323, 2012(anonymous peer-reviewed) 


\section{Politicization}

The innate qualities of a work of art, like its artistic expression, the art techniques, and the perception and intention are pre-determinants of the possibility of it becoming canonized. Extrinsic factors controlling the process are the selection and choice of the readership audience, critiques and interpretations by contemporaries, and the process of transmission to a wider audience and through generations.

In ancient times, the one individual audience member who had the ultimate decision-making power and greatest influence over the review, critique and interpretation of an art was the emperor. Where there was such intervention by the ruling monarch or when his court officials who sought to impress him displayed political inclination in their interpretation, politicization occurs.

The consequences or signs of politicization include:

1. Creation, naming and interpretation, or alteration of literature and art to serve a political interest or to re-arrange political agenda

2. Use of political power to compile and divide literature and art and influence the interpretation

3. Appraisal of the author and literature and art from political points of view

In the case of the Song of Everlasting Sorrow, the negative responses by critics culminated to a general avoidance of the use of this theme in paintings, in order not to compromise the norms in the value systems of the society and imperial court. In scholarly context, the intention to avoid offense to any groups in society is termed as 'political correctness'. The painting, The Emperor Hsüan-tsung's Flight to Shu, inspired by the An Lushan rebellion against the Tang dynasty in China, was renamed due to political concerns. Ye Mengde (1077-1148) recorded this anecdote in Bishu Luhua - the title of the painting was changed to Plucking Melon Painting circa the end of Northern Song and beginning of Southern Song. Although this theme did not enjoy widespread popularity, it nonetheless had been politicized.

The selection and naming conventions of the Eight Views of Yan Mountains (otherwise known as Eight Views of Yan capital) and Eight Views of Peking during the Jin and Yuan dynasties were not consistent. In the sixteenth year of Qianlong (1751), Emperor Qianlong systematised the naming conventions which is used to this day. He also emphasised that the Eight Views of Peking was birthed as a result of the imperial capital's magnificence.

It is obvious that there was a major change in the naming of Eight Views of Peking from the time of the Jin dynasty to the reign of Qianlong. Twilight Upon the Tomb of Dao (道陵夕照) was changed to Twilight Upon the Golden Platform (金臺夕照) for political reasons. Dao Ling refers to the tomb of the 
Jin emperor Zhang. This scene evoked feelings of melancholy which was not reflective of that era of peace and prosperity. ${ }^{3}$

Zhu Xi (1130-1200) emulated the traditional boat folk songs and composed Wuyi Boat Songs. With the spread of Zhu Xi's scholarly articles eastward, Joseon scholars followed the rhythm of Wuyi Boat Songs to paint and appreciate the beauty of Wuyi. However, they held different views on the original meaning of the Wuyi Boat Songs which were greatly influenced by the rise of neo-Confucianism. It was not till Joseon Jeongjo (1752-1800) ${ }^{4}$ compiled Zhu's poems in $\mathrm{Ya}$ Song that the imperial officials, after extensive discussion, decided to use Yuan dynasty Chen Pu's explanation - Wuyi Nine Bend Stream (Jiuqu Stream) is a holy place set aside for self-cultivation. Politicization has shrouded the pure bliss and jubilation of touring in mountains and rivers. 5

\section{Conceptualization}

Located in the province of Fujian, the nine-bend stream meanders through Mountain Wuyi from Huanggang Peak in the east to converge into Chong Stream in the west. The river bends are named in ordinal order - First Bend, Second Bend, Third Bend and so forth till the Ninth Bend; collectively, the nine bends are known as 'Wuyi Nine Bend Stream'. The neo-Confucian master, Zhu Xi, founded his academy, Wuyi Vihara, at the fifth bend of the stream; as his influence gradually expanded, the fame of Wuyi reached the shores of Korea peninsula where it was hailed as a paradise. When the Joseon scholars studied Zhu Xi's writings that were inundated with imagery of Wuyi Nine Bend Stream, they were drawn by the wonder of Mountain Wuyi and the Wuyi Nine Bend Stream. It was as if they were transported into the very place itself and they sang choruses of praises on its beauty and painted its scenic landscapes on canvas. By connecting all aspects of the pictorial narrative through what they have learnt from his writings, they conceptualized the scenery.

Another example in East Asia on the conceptualization of scenery is the

3 I Lo-fen, Of Cloud Shadows and Celestial Light: Poems and Paintings of the Landscape of Xiao Xiang (雲影天光:瀟湘山水之畫意與詩情). Taipei， Li Ren Publishing Co., 2013

4 I Lo-fen, "Wandering and Pursuing: Zhu Xi's Wuyi Boating Song and Follow Writings in Joseon Dynasty Korea"(遊觀與求道: 朱喜〈武夷櫂歌〉與朝鮮士人的理解與續作). Journal of Chinese Studies(中國文化研究所學報)60, pp. 53-71, Jan. 2015.

5 I Lo-fen, "Culture Images of the 'Wuyi Nine Gorges' in Ancient Korea: A Study on Printing and Publishing” (印刷出版與朝鮮「武夷九曲」文化意象的「理學化」建構). In Shi Shouqian, Liao Chao-Hen eds (石守謙、廖肇亨主編). Shaping the Culture Images of East Asia : Viewing, Media, Agents (轉接與跨界:東亞文化意象之傳佈). Taipei, Asian Culture Publishing (允晨出版社), pp.351-388, June. 2015 
Eight Views of Xiao Xiang. Prior to Northern Song scholar and artist Song Di's (circa 1015-1080) paintings of Eight Views of Xiao Xiang, there were historical records of paintings on the theme of Eight Views. Shen Kuo (1031-1095) of Northern Song in the book, Dream Torrent Essays (夢溪筆談), acknowledged Song Di as the originator of the concept of the Eight Views of Xiao Xiang, who conceived and named each of the eight scenes: Geese Descending on Level Sand; Returning Sails from Distant Shore; Mountain Market in Clearing Mist; River and Sky, Evening Snow; Autumn Moon over Lake Dongting; Night Rain on Xiao Xiang, Evening Bell from Mist-shrouded Temple; and Fishing Village in Twilight Glow. 6

The Eight Views of Xiao Xiang is not a literal copy of specific sights but rather a series of four-character one-line poetic titles that allow artists to find new opportunities and express specific themes on natural landscapes, seasons, weather and human activities. With the exception of two scenes, namely Autumn Moon over Lake Dongting and Night Rain on Xiao Xiang which respectively correspond to Lake Dongting and Lingling County in the province of Hunan where the Xiao and Xiang rivers converge, the rest of the scenes are not referenced to any particular location. Consequently, the theme of Eight Views of Xiao Xiang is popularly accepted and easily reproduced.

Diplomats and artists, during the twelfth century, brought Eight Views of Xiao Xiang's poetry-painting to Goryeo; in the $13^{\text {th }}$ century, monks travelling eastwards introduced the theme of Xiao Xiang into Japan. The characteristics and profiles of the intermediaries determined the discourse of the development of conceptualization in different places. ${ }^{7}$

A high level of conceptualization in East Asian scenery is revealed in the Legend of Peach Blossom Shangri-La. The legend describes an ethereal utopia where its people live peacefully, unaware of the harsh realities of the outside world. Paradise, secret place, dream land, ideal society - the richness of human imagination is articulated through the diversity of these explicit concepts.

Wuyi Nine Bend is a place that exists in real life. To the majority who are unable to visit the place in person, they learn of it through books and illustrations and become acquainted with the concept of its cultural geography - this is known as 'conceptual landscape'.

In contrast, the popular painting theme of Eight Views of Xiao Xiang as

6 Shen Kuo沈括, Xin Jiaozheng Mengxi Bitan新校正夢溪筆談 (Brush talks from Dream Brook), ed. Hu Daojing胡道靜 (Hong Kong: Chung Hwa Book Co., 1987), 17, p171。

7 I Lo-fen, “The Eight Views of Xiao Xiang: East Asian Cultural Image” (瀟湘八景: 東亞共同母題的文化意象” Journal of the History of Ideas in East Asia (東亞觀念史集 刊), 6, pp.35-55, June 2014 (THCI) 
well as the literary classic, Legend of the Peach Blossom Shangri-La do not portray real geographical places. Yet for many centuries, this has not stopped many from getting intrigued and attempting to define an actual location; this even became a fad during the tourism boom of the Ming Dynasty. However, even if someone were to pinpoint the locations of Eight Views of Xiao Xiang on the map, it would be a fallacious attempt. It is the enigmatic multiplicity of Eight Views of Xiao Xiang and Legend of the Peach Blossom Shangri-La that provides the basis to the notion of conceptual landscape. The essence of conceptualization emphasizes on the openness between signifier (possible pinpointing of the location of Eight Views of Xiao Xiang) and signified (actual location of the place of interest), and the degree of freedom in getting away from unilateral and closed discourses.

\section{Abstraction}

The degree of freedom in conceptual landscape leads to the abstraction of the concept. Using again the Legend of Peach Blossoms Shangri-La as example, Tao Yuanming described in his fable a fishing village and a fictitious paradise where a group of villagers led their lives unaware of the outside world. Future generations led the fable through the process of canonization. After canonization, the limelight is given to the paradise whereas the earthly existence faints in comparison.

After the process of conceptualization, the Legend of the Peach Blossom Shangri-La became a conceptual landscape; it may allude to fairyland, secret places, dream world, utopia and the likes. The subsequent process of abstraction converts it from a pronoun to an adjective and it takes on the form of paradise that has properties of mobility and transferability.

The process of abstraction of an art is likened to a second refinement process. The weaker the links between signifier and signified, the looser the association or referencing, therefore the easier it is, through the process of abstraction, to engage in people's minds. From the aesthetic point of view, this impression formed and etched in people's minds is known as the 'cultural image'.

Culture (文化), in the context of 'cultural image (文化意象)', is the macro perspective and medium of transmission of the image (意象). 'Yi' (意) is likened to the aesthetics sub-consciousness of the inner spirit and the projection of the aesthetic sub-consciousness into aesthetic objects is the 'Xiang' (象). The combination of the two reflects the aesthetic consciousness of the place or the era, the judgement on aesthetics and the value systems. ${ }^{8}$

8 I Lo-fen, "Understanding East Asian Civilization from the Perspective of Culture Images"(從文化意象理解東亞文明). The New Plan for Asian Civilization and its 
The Legend of the Peach Blossom Shangri-La, the Eight Views of Xiao Xiang, Wuyi Nine Bend and other classics form the cultural image of multiple East Asian countries, yet at the same time, each expresses its own individuality. The East Asian cultural image commonly uses Chinese characters, and from the artistic point of view, presents itself in multiple facets with very different expressions. Unconstrained by space and time, the cultural image becomes the carrier for cultural exchange and communication in East Asia.

\section{Localization}

If conceptual landscape, through the process of abstraction, is elevated to the philosophical and aesthetic level, localization surpasses it by grafting and transplanting the external arts onto the local scene. Whether it's a real physical location like Wuyi Nine Bend or a cultural geographical place like the Eight Views of Xiao Xiang, to migrate from its point of origin and transmit to other places, gain acceptance from the locals and finally reinvent to adapt to the new environment, depends on localization.

Despite never having been to Wuyi Nine Bend in China, the Joseon scholars absorbed the concept of Nine Bend and named many places of scenic beauty in Korea after it, such as Guyun Nine Bend, Huayang Nine Bend. Wuyi Nine Bend stream flows from Fujian to Jiangxi and people of old used bamboo rafts to travel upstream in preference over navigating through the tough terrains via the mountain routes. Therefore, the river bends are named in ordinal order from east to west. However, the topography of the Korean peninsula differs from China. When replicating the Nine Bend, the historic and cultural values in the new place must be taken into consideration and yet the rationale behind the naming of the Nine Bend cannot be ignored. "Learning is like going against the current - where there is no persistence and constant improvement, backsliding will result". This spirit of learning and cultivation is inspired by the journey upstream against the current flow. Therefore, through localization, the naming of the river bends during the Joseon era in Korea is from west to east.

The Eight Views of Xiao Xiang does not refer to an actual earthly place but the name, Xiao Xiang, confines it within the boundaries of Hunan province. Southern Song artists may not have had the opportunities to travel to Hunan to paint eight scenes of Xiao Xiang and so abstracted Xiao Xiang from the Eight Views of Xiao Xiang and substituted it with scenic places within their sights. For example, Mi Youren's painting, Magnificence of Xiao Xiang is inspired by the splendour of Zhenjiang, Muqi's painting, The Eight Views of Xiao Xiang depicts, in reality, the surroundings around the West Lake. The 
phenomenon of localization strengthen the tenacity and openness of the Eight Views of Xiao Xiang. Since Xiao Xiang need not be geographically confined to Hunan, Eight Views may sprout in any place. In China, there are Eight Views of Peking, Eight Views of Jinling etc; in Korean peninsula, there are Eight Views of Pusan, Eight Views of Danyang etc; in Japan, there are Eight Views of Kanazawa, Eight Views of Oumi etc; the Ryukyu Islands, Taiwan, Hong Kong and Singapore have rich cultural heritage of East Asian Eight Views.

\section{Standardization}

There is a premise to the localization of Eight Views and Nine Bend in East Asia and that is known as 'standardization'. Due to the topographical terrain, Guyun Nine Bend in the Korean peninsula is named in the opposite direction as Wuyi Nine Bend in China. On the surface, they seem to differ but in actual fact, they adhere to the intrinsic symbolism of "navigating the raft against the current".

Internal standardization needs to be pondered upon whereas external standardization is easy to comprehend. For example, naming convention follows the Eight Views of $X X$ and $X X$ Nine Bend. In general, each of the eight scenes in the Eight Views of $X X$ has a four-character one-line poetic title; the river bends in $X X$ Nine Bend are named in ordinal order - First Bend, Second Bend, Third Bend and so forth till the Ninth Bend. As such, there is a model for duplication and reinvention.

It could also be observed that paintings with the same theme have the same composition and elements. This is illustrated by the example of the theme of the gathering at Lanting Pavilion. Paintings on this theme invariably depict human activities besides a meandering stream against a backdrop of lofty mountains and majesty ranges, as described in the Preface of the Orchid Pavilion, and emulate Wang Xizhi's calligraphy techniques as inspired through his observation of geese swimming on water. This compositional model spread to Japan and Korea where it is adopted by the local painters.

The paintings of Su Shi and his companions on a night tour of the Red Cliffs also show similar process of standardization. Artists typically paint $\mathrm{Su}$ Shi and his two friends sailing in a small boat with Su Shi turning back to watch the majestic waterfall thundering down the red cliffs. Japanese and Korean paintings of the Red Cliffs also have identical depictions. This type of repetition aids the viewers in recognizing the form of expression and leads to the development of the standardization model. Another instance is Chinese paintings on Wuyi Nine Bend; Nine Bend paintings during the Joseon period in Korea derived the standardization model from the maps published in Atlas of Wuyi Mountains and other geographical books. Artworks may be in the 
form of print or paintings and may also be reproduced on pottery ware.

The paintings of Autumn Moon over Lake Dongting by Joseon painters Jeong Seon (1676-1759) and Sim Sa-jeong (1707-1769) depict the Yueyang Tower on the right side and a flag at the top of the tower. There are small boats on the lake and mountains in the far horizons; a full moon hangs high in the sky. The same standard may be observed in Korean folk paintings as well as blue and white porcelain produced in the eighteenth and nineteenth centuries. The Leeum Museum, National Museum of Korea, the Museum of Oriental Ceramics in Osaka, own extensive collections of East Asian ceramics, which originates mainly from ancient China and Korea. Even though the shapes and sizes are different, one may observe striking resemblance in the artwork. By interpreting the artwork on the blue and white porcelain, we could determine the painting theme despite the lack of labelling on the pottery ware.

\section{Modularization}

Standardization makes duplication easy; modularization is the simplifying of product parts to increase the potential for product variety. The localized Eight Views of $X X$ in East Asia is used to demonstrate this point. The comparison of the eight four-character-one-line poetic titles in the Eight Views of Xiao Xiang and the Japanese variant, the Eight Views of Kanazawa, are illustrated in the table below.

\author{
潚湘八景 \\ Eight Views of Xiao Xiang \\ 潚湘夜雨 \\ Night Rain Over Xiao Xiang \\ 煙寺晚鐘 \\ Evening Bell from a Mist-Shrouded Temple \\ 遠浦歸帆 \\ Returning Sails from Distant Shores \\ 山市晴嵐 \\ Mountain Market in Clearing Mist \\ 洞庭秋月 \\ Autumn Moon Over Lake Dongting \\ 平沙落雁 \\ Geese Descending on Level Sand \\ 漁村夕照 \\ Evening Glow Over Fishing Village
}

\author{
金澤八景 \\ Eight Views of Kanazawa \\ 小泉夜雨 \\ Night Rain Over Koizumi \\ 稱名晚鐘 \\ Evening Bell from Shōmyō \\ 乙憈歸帆 \\ Returning Sails at Otoko Beach \\ 洲崎晴嵐 \\ Clearing Weather at Susaki \\ 瀨戶秋月 \\ Autumn Moon Over Seto \\ 平潟落雁 \\ Geese Descending at Hiragata \\ 野島夕照 \\ Evening Glow at Nojima
}


江天暮雪

Fishing Village in Twilight Snow
內川暮雪

Uchikawa in Twilight Snow

The title of each scene of the Eight Views of Kanazawa is created by substituting the first two characters with the names of the local places. For example, 'Shōmyō (稱名)' in Evening Bell from Shomyo-ji Temple (稱名晚鐘) refers to 'Shomyo-ji Temple'. 'Evening Bell (晚鐘)' and 'Clearing Mist (晴 嵐)'act as the modules for easy assembly.

Another way to recreate the Eight Views of Xiao Xiang is to use the poetry of the Eight Views of Xiao Xiang as modules. In the same way, sixteenth century Japanese painter Unkei Eii's painting of the Eight Views of Xiao Xiang drew inspiration from Southern Song Yu Jian's Eight Views of Xiao Xiang poetry. Kim Hyeon-seong's (1542-1621) painting of Eight Views of Xiao Xiang on a screen (now owned by Kyushu National Museum) was prompted by Goryeo poet, Jin Hwa's poetry on the Eight Views of Xiao Xiang. Jin Hwa's poetry imitated Shi Huihong's colophons on Song Di's Eight Views of Xiao Xiang. This came about as an outcome of modularization of Shi Huihong's poetry.

Using 'meandering stream' as a module, ancient Japan and Korea people imitated the gathering at China's Lanting Pavilion and organised similar gatherings beside a winding stream on the third day of March. During the Joseon era, the idea and essence of a gathering of old men in Bai Juyi's painting of The Nine Old Men at Mountain Xiangshan was assimilated into their lives. ${ }^{9}$ Works that are extant till this day include the Painting of Jinlan Gathering that is now housed at the National Museum of Korea.

Wang Xizhi's Preface of the Orchid Pavilion is a classic piece of work in East Asia. The gathering in the ninth year of Emperor Yonghe's reign was not for the sake of forming alliances; contrary to that thinking, with the rise of Confucianism in that era, the gathering was an opportunity to discuss and perpetuate Confucius' teachings, and conduct purification rituals. Joseon literari localized the gathering at Lanting Pavilion in their paintings and created their own version of Jinlan Gathering. Their paintings would depict a meandering stream and the people in the paintings were clothed in Korean costumes from the Joseon period. With the exception of the people in different dressing, the same composition and elements of Painting of Lanting Pavilion may be observed. The fact that the Painting of Jinlan Gathering is a replica of the Painting of Lanting Pavilion may only be explained by Text and

9 I Lo-fen, “Calligraphy and Paintings on Lan Ting Xu in Ancient Korea”(蘭亭流芳在 朝鮮). The International Conference on Lan Ting Xu, Oct, 2011, Beijing, National Palace Museum, China 
Image Studies and its seven-pronged approach in analysing the cultural diffusion within East Asia.

\section{Conclusion}

In this article, the Text and Image Studies and its seven-pronged approachcanonization, politicization, conceptualization, abstraction, localization, standardization, modularization - is employed to explore the theory in East Asian cultural diffusion. Some of these approaches occur on their own whilst others are intricately linked to each other. By applying the seven-pronged approach on theoretical level with case studies, we are able to understand the historical influence of Text and Image Studies in the development of East Asian cultural exchange.

As mentioned in the earlier part of the article, Text and Image Studies may also be applied to creativity and innovation. In today's production and consumption terms, the seven-pronged approach can be understood in the following strategies.

Canonization: $\quad$ Brand building so as to make it instantly recognizable and become a well-known brand.

Politicization: Relationship and distance between high profile endorsement versus masses' thinking

Conceptualization: Brand positioning

Abstraction:

Lead the fashion trend and establish rapport with consumers

Localization: $\quad$ Build intimacy with the product and interaction with consumers

Standardization: Easy to reproduce and disseminate to attract human/ internet traffic

Modularization: Separate according to functions and reassemble to serve the needs of individual consumers 